\title{
Can direct smear results that are routinely collected at health centre level be used for monitoring the impact of mass drug administration with praziquantel on schistosomiasis in Burundi? A preliminary assessment
}

Paul BIZIMANA ( $\square$ pbizimana2010@gmail.com )

Institut National deSanté Publique

Katja POLMAN

Institute of Tropical Medicine

Giuseppina ORTU

Global health consultant

Meryam KRIT

Institute of Tropical Medicine

Frédéric NSABIYUMVA

Université du Burundi

Audace NKESHIMANA

Institut National de Santé Publique

Urlich BIJABUKA

Institut Universitaire des Sciences de la Santé et de Développement Communautaire

Marceline NIBAKIRE

Bureau de la Municipalité Sanitaire de Bujumbura

Jean-Pierre VAN GEERTRUYDEN

University of Antwerp

\section{Research}

Keywords: Direct smear, Routine data, Health centre, Monitoring, Mass drug administration, Praziquantel, Schistosomiasis, Burundi

Posted Date: December 31st, 2019

DOI: https://doi.org/10.21203/rs.2.19785/v1 
License: (c) (1) This work is licensed under a Creative Commons Attribution 4.0 International License. Read Full License

Version of Record: A version of this preprint was published at Parasites \& Vectors on April 21st, 2020. See the published version at https://doi.org/10.1186/s13071-020-04076-4. 


\section{Abstract}

\section{Background}

Intestinal schistosomiasis is still a public health problem in Burundi. Since 2008, annual mass drug administration (MDA) with praziquantel have been rolled out in 11 endemic districts. The national programme relies on school based surveys with Kato-Katz (KK) to monitor the impact of MDA. We explored whether routine data on intestinal schistosomiasis as determined by direct fecal smears (DS) at health centre $(\mathrm{HC})$ level could be used.

\section{Methods}

We collected routine incidence data on intestinal schistosomiasis from the Burundian National Health Information System. These data concerned the number of intestinal schistosomiasis cases as detected by DS examination in the HC of all 45 sanitary districts (SD) between 2011 and 2015. A temporal trends analysis was performed using mixed Negative Binomial regression. Sanitary districts with MDA campaigns with praziquantel $(n=11)$ were compared with those without $(n=34)$. In addition, KK-based prevalence data from a school-based national mapping in 2014 were compared with the DS-based incidence data in the 45 SD.

\section{Results}

In the 11 SD applying MDA with praziquantel, the incidence rate decreased significantly for the years $2014\left(\beta_{2014}=-0.826, p=0.010\right)$ and $2015\left(\beta_{2015}=-1.294, p<0.001\right)$ and for the five-year period $(\beta=-0.286$, $p<0.001)$, whereas in the 34 districts without MDA, there was no significant trend $(\beta=-0.087, p=0.219)$. In most of the 45 SD, the low prevalences based on $\mathrm{KK}$ in school children were confirmed by low incidence rates based on DS in the HC.

\section{Conclusions}

The results of this preliminary study suggest that routine surveillance data at $\mathrm{HC}$ level, may be able to monitor the impact of MDA with praziquantel on intestinal schistosomiasis in Burundi. However, more sensitive POC diagnostic tests, such as the POC-CCA assay are desirable when moving from control to elimination of schistosomiasis. Elimination of intestinal schistosomiasis calls for integration of adequate diagnosis and treatment into routine activities of primary health care facilities.

\section{Background}

Schistosomiasis is a parasitic disease caused by the genus Schistosoma [1,2]. It is one of the Neglected Tropical Diseases (NTD). Linked to poverty, schistosomiasis is more prevalent in countries and regions where hygienic conditions are precarious and access to safe water and adequate sanitation is limited [2]. Between 200 and 250 million of people in the world are infected [3], and 600-780 million are at risk [3,4]. 
The sub-Saharan Africa countries are the most affected by this disease, with more than $90 \%$ of the total burden $[5,6]$.

In Burundi, intestinal schistosomiasis has been a public health challenge for many decades $[7,8]$. According to a nationwide school-based survey performed in 2007, based on the Kato-Katz (KK) test [9], 11 out of the 45 sanitary districts (SD) in Burundi were considered at risk of intestinal schistosomiasis. Since 2008, these 11 SD have been targeted for annual mass drug administration (MDA) with praziquantel (PZQ) to school-age children between five and 15 years old [9].

To measure the impact of MDA, epidemiological surveys using KK test were performed in a number of primary schools, chosen as sentinel sites [10]. These surveys demonstrated a decrease in S. mansoni infection from 12.7\% in 2007 (baseline) to $1.1 \%$ in 2011 [10].

After six years of annual MDA in the targeted areas, a school-based national mapping was implemented to reassess the extent of the schistosomiasis problem, and to determine whether it was possible to move to the elimination phase [10]. The results from the KK test showed that there was a decline in the prevalence of infection, from $12.7 \%$ in 2007 (baseline) to $2.2 \%$ in 2014 [10].

Although the epidemiological surveys in sentinel sites and the national mapping provide a good estimation of the prevalence of schistosomiasis after several years of MDA, it is a very laborious and costly undertaking [11,12], and often requires external financial support, especially in resource-limited countries such as Burundi $[9,10]$. It is therefore important to look for other cost-effective and sustainable strategies to monitor the impact of MDA campaigns.

In this paper we aim to evaluate whether routine data on intestinal schistosomiasis as determined by direct smear (DS) stool examination and reported by health centres $(\mathrm{HC})$ to the Directorate of National Health Information System (DNHIS), could be used as an approach to monitor the impact of MDA on intestinal schistosomiasis in Burundi.

\section{Methods}

\section{Functioning of the National Health Information System}

The Burundian National Health Information System (NHIS) consists of three levels: the peripheral level (sanitary districts=SD) with $\mathrm{HC}$ and district hospitals $(\mathrm{DH})$; the intermediate level (sanitary provinces=SP) with regional hospitals; and the central level (DNHIS) with national and specialised hospitals. Routine data on diseases registered in consultations and laboratory (e.g. malaria, diarrhoea, schistosomiasis) are collected from each $\mathrm{HC}$ and reported to the SD, which reports in turn to the SP, and the SP reports to the DNHIS. For hospitals, they report to the SD or to the SP or to the DNHIS, according to the level they belong to. Reporting is done monthly for more than $95 \%$ of diseases, including intestinal schistosomiasis.

\section{Data collection}


In 2017, routine data on intestinal schistosomiasis were collected from the DNHIS. The data concerned all intestinal schistosomiasis cases as determined by DS and reported by the HC from each SD during the period 2011 to 2015. They were used for this study with the authorisation of the ministry of health (MoH). Data from hospitals were not collected to avoid duplicates as hospitals receive patients referred by HC.

\section{Data analysis}

We described the number of reported cases based on DS detection per year in each SDover a period of 5 years. For the year 2014, with a focus on 2014, where the DS based-incidences at HC level could be compared with the KK-based prevalence in school children.

We analysed temporal trends in intestinal schistosomiasis incident cases for each year in the $11 \mathrm{SD}$ targeted by MDA campaigns (zone of intervention-ZI) with PZQ, and compared them with those in the 34 remaining SD (zone of non-intervention-ZNI), to allow for any general trend in intestinal schistosomiasis, not related to annual MDA by PZQ.

The number of intestinal schistosomiasis cases reported each year were put on a logarithmic scale. The slope should be linear if the incidence remained identical, despite the progressive growth of the population at risk (assumed to be identic for all SD, after the general census of 2008). The effect of MDA campaigns on the annual incidence of intestinal schistosomiasis should manifest itself as a significant change in the slope.

A mixed Negative Binomial regression was performed due to the overdispersion of the data $[13,14]$. A random effect was added to take into account the existing correlation in the data per district over time. The trends of the number of intestinal schistosomiasis cases reported each year were compared between $\mathrm{ZI}$ and ZNI. The respective slopes $\beta_{\mathrm{i}} \mathrm{i}=2012,2013,2014,2015$, were estimated to compare the trends in $\mathrm{ZI}$ and ZNI each year $(2012,2013,2014$ and 2015) to the reference year 2011. A second analysis was performed, for which only one slope $\beta$ was estimated to study the overall trend during the period of 5 years (from 2011 to 2015). The slope estimation was given for both zones ZI and ZNI. Stata version 12 (Stata Corp. LP, College Station, United States of America) software was used to calculate the slopes with an a risk error of $5 \%$.

\section{Results}

The routine data obtained by DS showed a decreasing schistosomiasis incidence rate in the majority of the SD in the $\mathrm{ZI}$, and a stable incidence rate in the majority of the SD in the ZNI. However, there were some exceptions in both zones. In the ZI, the incidence rate in the SD of Rumonge remained stable over time, and in the ZNI, the incidence rates in some of the SD decreased, while they increased in others (Table 1).

We were able to compare the data of 2014 (Figure 2) where both districtwide routine surveillance data and school-based mapping data were available. In most SD the low prevalence was confirmed by a low 
incidence rate. However, in some SD (e.g. Bururi, Gitega, Musema, Zone Centre) the prevalence rate was zero, while routine surveillance detected some cases. The two districts with the highest prevalences also showed the highest incidence rates, but relatively high incidence rates were also seen in SD with lower prevalences.

Table 2 shows the results of the temporal trends analysis. Both in the $\mathrm{ZI}$ and the $\mathrm{ZNI}$, the incidence rate decreased, but this only reached significance in the ZI for $2014\left(\beta_{2014}=-0.826, p=0.010\right)$ and 2015 $\left(\beta_{2015}=-1.294, p<0.001\right)$. The overall trend over the five years period (2011 to 2015) showed a highly significant decrease in the $\mathrm{ZI}(\beta=-0.286, p<0.001)$, while no significant trend was observed in the $\mathrm{ZNI}$ $(\beta=-0.087, p=0.219)$. (Figure 1).

\section{Discussion}

MDA campaigns with PZQ are recommended for the control of schistosomiasis [15-17] and constitute the current national strategy for schistosomiasis control in Burundi [18]. The KK test is still the primary diagnostic tool in monitoring the impact of national school based deworming programmes on $S$. mansoni infection [15,17], but it is not available in Burundi as a routine test at PHC level. The only test available for diagnosis of intestinal schistosomiasis in Burundian HC is the DS [18]. We explored whether DS results that are routinely collected at $\mathrm{HC}$ level could give an indication of the impact of MDA with praziquantel on S. mansoni infection in Burundi as well. We did this by comparing temporal trends in intestinal schistosomiasis as determined by DS in HC of ZI with those in NZI $[19,20]$. A decreasing trend was observed in the $\mathrm{ZI}$, but not in the ZNI. The decreasing trend in the ZI was in line with the decline in schistosomiasis prevalence from $12.7 \%$ in 2007 to $2.2 \%$ in 2014 as observed with the gold standard KK test [15] performed in the epidemiological surveys in sentinel sites and in the national mapping [10]. Moreover, comparison of routine surveillance data with school-based mapping data per SD in 2014 showed that for most SD low prevalences based on KK were confirmed by low incidence rates by DS, and that in some districts where the prevalence with $\mathrm{KK}$ was zero, routine surveillance still detected some cases.

In contemporary Burundi, schistosomiasis transmission is low to moderate, the health care system is weak and the (national) resources for health care limited. Furthermore, schistosomiasis diagnosis through $\mathrm{KK}$ and treatment of positive cases with $\mathrm{PZQ}$ is absent in the primary health care setting. Despite these limitations, the current passive routine surveillance system of Burundi appears still be able to monitor the evolution of schistosomiasis in the $\mathrm{ZI}$ as well as in the ZNI. Both are equally important in the framework of disease elimination.

Our data hold promise for the use of routine diagnostic data collected at $\mathrm{HC}$ level as a cost-effective and sustainable strategy to monitor the impact of MDA campaigns and other schistosomiasis control interventions in Burundi. However, it should be borne in mind that DS, but also KK, have a reduced sensitivity especially in areas of low endemicity, such as Burundi [10]. Highly sensitive diagnostic tools to detect light-intensity infections are pivotal for monitoring progress from control towards elimination [21- 
23]. Several studies have now documented the lateral flow immunochromatographic point-of-care (POC) test detecting Schistosoma circulating cathodic antigen (CCA) in urine as a valuable alternative to the KK for the diagnosis of $S$. mansoni [24]. It is rapid, user-friendly, and considerably more sensitive than KK especially in areas of low prevalence [25]. While the POC-CCA assay has already shown its value as a mapping and monitoring in national control programmes [10,24], its suitability for integration into the $\mathrm{PHC}$ system as a routine test for case management and surveillance/monitoring of intestinal schistosomiasis still needs to be investigated in more detail. Burundi is low endemic for intestinal schistosomiasis and currently aiming for elimination [10]. This, in combination with a relatively wellfunctioning NHIS system, would provide an ideal setting for such a study.

\section{Conclusions}

The results of this preliminary study suggest that routine surveillance at $\mathrm{HC}$ level may be able to monitor the impact of MDA with PZQ on intestinal schistosomiasis in Burundi. However, more sensitive routine diagnostic tests, such as the POC-CCA assay are desirable when moving from control to elimination of schistosomiasis. Further integration of adequate diagnosis and treatment into the routine activities of primary health care facilities is essential for intestinal schistosomiasis to be eliminated in Burundi.

\section{Abbreviations}

CCA: circulating cathodic antigen; DH: district hospital; DNHIS: directorate of national health information system; DS: direct smear; HC: health centre; HF: health facility; KK: kato-katz; MDA: mass drug administration; NHIS: national health information system; NTD: neglected tropical diseases; p: p-value; PHC: primary health care; PZQ: praziquantel; SCl: schistosomiasis control initiative; SD: sanitary district; SP: sanitary province; WHO: world health organization, ZI: zone of intervention; ZNI: zone of nonintervention

\section{Declarations}

\section{Acknowledgements}

Authors appreciated also the Director of the Schistosomiasis Control Initiative, Prof Alan Fenwick, for supporting this project. They are also very thankful to the Ministry of Health of Burundi, the Schistosomiasis Consortium for Operational Research and Evaluation (SCORE), and the Schistosomiasis Control Initiative (SCl) for the data from the national mapping of 2014 used in this study. They also express their thanks to the staff of the DNIHS who helped to get these data.

\section{Authors' contributions}

PB involved in the acquisition, analysis and interpretation of data for the study and wrote the paper. KP made substantial contributions to the conception of the study, analysed and interpreted data and revised the manuscript critically. GO involved in the conception of the study, analysis and interpretation of data 
and revision of the manuscript. MK involved in conception of the methodology, analysis and interpretation of data and revised the manuscript. JPVG: made substantial contributions to the conception of the study, analysis, and interpretation of data, critically revised the manuscript. FN, AN, UB and $\mathrm{MN}$ were revised the manuscript. All authors read and approved the final manuscript.

\section{Ethics approval and consent to participate}

The research protocol was reviewed and approved by the National Ethics Committee of Burundi in September 2013. Authorisation from the Ministry of Public Health for the study was provided in May 2014.

\section{Consent for publication}

Not applicable.

\section{Availability of data and materials}

The datasets generated and analysed during the current study are available from the corresponding author on reasonable request.

\section{Competing interests}

The authors declare that they have no competing interests.

\section{Funding}

The Schistosomiasis Control Initiative (SCI)/Imperial College and VLIR-UOS funded this study.

\section{Author details}

${ }^{1}$ Global Health Institute, Department of Epidemiology and Social Medicine, Faculty of Medicine and Health Sciences, University of Antwerp, Antwerp, Belgium ${ }^{2}$ Département des Sciences de la Santé Publique, Direction de la Formation, Institut National de Santé Publique, Bujumbura, Burundi ${ }^{3}$ Département de Médecine Communautaire, Faculté de Médecine de Bujumbura, Université du Burundi, Bujumbura, Burundi ${ }^{4}$ Département des Sciences de la Santé Publique, Institut Universitaire des Sciences de la Santé et de Développement Communautaire, Bujumbura, Burundi ${ }^{5}$ Faculté de Médecine, Université de Ngozi, Ngozi, Burundi ${ }^{6}$ Medical Helminthology Unit, Department of Biomedical Sciences, Institute of Tropical Medicine, Antwerp, Belgium ${ }^{7}$ Section of Infectious Diseases, VU University in Amsterdam, Amsterdam, The Netherlands ${ }^{8}$ Global Health Consultant, London United Kingdom ${ }^{9}$ Biostatistics and Epidemiology Unit, Biomedical Department, Institute of Tropical Medicine, Antwerp, Belgium

${ }^{10}$ Département de Médecine Interne, Faculté de Médecine de Bujumbura, Université du Burundi, Bujumbura, Burundi ${ }^{11}$ Bureau de la Municipalité Sanitaire de Bujumbura, Ministère de la Santé Publique et de la Lutte contre le Sida, Bujumbura, Burundi 


\section{References}

1. Gryseels B, Polman K, Clerinx J, Kestens L. Human schistosomiasis. Lancet 2006; 368:1106-18.

2. Raso G, Vounatsou P, McManus DP, N'Goran EK, Utzinger J. A Bayesian approach to estimate the age-specific prevalence of Schistosoma mansoni and implications for schistosomiasis control. Int $\mathrm{J}$ Parasitol 2007; 37:1491-500.

3. Steinmann P, Keiser J, Bos R, Tanner M, Utzinger J. Schistosomiasis and water resources development: systematic review, meta-analysis, and estimates of people at risk. Lancet Infect Dis 2006; 6:411-25.

4. Clements AC, Brooker S, Nyandindi U, Fenwick A, Blair L. Bayesian spatial analysis of a national urinary schistosomiasis questionnaire to assist geographic targeting of schistosomiasis control in Tanzania, East Africa. Int J Parasitol 2008; 38:401-15.

5. Chitsulo L, Engels D, Montresor A, Savioli L. The global status of schistosomiasis and its control. Acta Trop 2000; 77:41-51.

6. Tchouanguem HN, Fouelifack FY, Keugoung B, Fouelifa LD, Moyou RS. [Current status of schistosomiasis in Santchou health area, (Santchou Health District, Cameroon western region)]. Pan Afr Med J 2016; 24:137.

7. F. de Bève. Bilhariziose en Ruanda-Urundi et spécialement à Usumbura. Annales de la Société Belge de Médecine Tropicale 1935; XV:3-18.

8. Neujan G. Le parasitisme intestinal chez les indigènes des Hauts Plateaux(environs de Kitega). Annale de la Société Belge de Médecine Tropicale 1937; XVII:343-9.

9. Ndayishimiye O, Ortu G, Soares Magalhaes RJ, Clements A, Willems J, Whitton J et al. Control of neglected tropical diseases in Burundi: partnerships, achievements, challenges, and lessons learned after four years of programme implementation. PLoS Negl Trop Dis 2014; 8:e2684.

10. Ortu G, Ndayishimiye O, Clements M, Kayugi D, Campbell CH, Jr., Lamine MS et al. Countrywide Reassessment of Schistosoma mansoni Infection in Burundi Using a Urine-Circulating Cathodic Antigen Rapid Test: Informing the National Control Program. Am J Trop Med Hyg 2017.

11. Sousa-Figueiredo JC, Stanton MC, Katokele S, Arinaitwe M, Adriko M, Balfour L et al. Mapping of Schistosomiasis and Soil-Transmitted Helminths in Namibia: The First Large-Scale Protocol to Formally Include Rapid Diagnostic Tests. PLoS Negl Trop Dis 2015; 9:e0003831.

12. Worrell CM, Bartoces M, Karanja DM, Ochola EA, Matete DO, Mwinzi PN et al. Cost analysis of tests for the detection of Schistosoma mansoni infection in children in western Kenya. Am J Trop Med Hyg 2015; 92:1233-39.

13. Gardner W, Mulvey EP, Shaw EC: Regression analyses of counts and rates: Poisson, overdispersed Poisson, and negative binomial models. Psychol Bull 1995; 118:392-404.

14. Verbeke G, Molenberghs G. Linear Mixed Models for Longitudinal Data. Springer, New York, 2000.

15. WHO. The control of schistosomiasis.World Health Organ Tech Rep Ser. 1993; 830:1-86. 
16. WHO. Schistosomiasis and soil-transmitted helminthiasis: prevention and control.World Health Organ Tech Rep Ser. 2004; 912:29-55.

17. WHO. Schistosomiasis and soil-transmitted helminthiasis: prevention and control.World Health Organ Tech Rep Ser. 2002; 912:25-50.

18. Bizimana P, Polman K, Van Geertruyden JP, Nsabiyumva F, Ngenzebuhoro C, Muhimpundu E et al. Capacity gaps in health facilities for case management of intestinal schistosomiasis and soiltransmitted helminthiasis in Burundi. Infect Dis Poverty 2018; 7: 66.

19. Engels D, Nahimana S, Gryseels B. Comparison of the direct faecal smear and two thick smear techniques for the diagnosis of intestinal parasitic infections. Trans R Soc Trop Med Hyg 1996; 90:523-25.

20. WHO. Basic Laboratory methods in medical parasitology. Geneva, World Heal Organization 1991:169.

21. Rollinson D, Knopp S, Levitz S, Stothard JR, Tchuem Tchuente LA, Garba A et al. Time to set the agenda for schistosomiasis elimination. Acta Trop 2013; 128:423-40.

22. Adriko M, Standley CJ, Tinkitina B, Tukahebwa EM, Fenwick A, Fleming FM et al. Evaluation of circulating cathodic antigen (CCA) urine-cassette assay as a survey tool for Schistosoma mansoni in different transmission settings within Bugiri District, Uganda. Acta Trop 2014; 136:50-7.

23. Lamberton PH, Kabatereine NB, Oguttu DW, Fenwick A, Webster JP. Sensitivity and specificity of multiple Kato-Katz thick smears and a circulating cathodic antigen test for Schistosoma mansoni diagnosis pre- and post-repeated-praziquantel treatment. PLoS Negl Trop Dis 2014; 8:e3139.

24. Sousa-Figueiredo JC, Betson M, Kabatereine NB, Stothard JR. The urine circulating cathodic antigen (CCA) dipstick: a valid substitute for microscopy for mapping and point-of-care diagnosis of intestinal schistosomiasis. PLoS Negl Trop Dis 2013; 7:e2008.

25. Kittur N, Castleman JD, Campbell CH, King CH, Colley DG. Comparison of Schistosoma mansoni Prevalence and Intensity of Infection, as Determined by the Circulating Cathodic Antigen Urine Assay or by the Kato-Katz Fecal Assay: A Systematic Review. Am J Trop Med Hyg 2016; 94:605-10.

\section{Tables}

Table 1 Number of intestinal schistosomiasis cases per SD and per year as determined by direct smear at HC level in Burundi. 


\begin{tabular}{|c|c|c|c|c|c|c|}
\hline SD name & ZONE & 2011 & 2012 & 2013 & 2014 & 2015 \\
\hline Bubanza & ZNI & 99 & 78 & 36 & 143 & 63 \\
\hline Rwibaga & ZNI & 103 & 14 & 0 & 2 & 6 \\
\hline Bururi & ZNI & 8 & 1 & 2 & 14 & 22 \\
\hline Matana & ZNI & 32 & 9 & 21 & 19 & 20 \\
\hline Cankuzo & ZNI & 10 & 1 & 0 & 2 & 0 \\
\hline Murore & ZNI & 1 & 18 & 4 & 0 & 0 \\
\hline Mabayi & ZNI & 64 & 74 & 38 & 30 & 53 \\
\hline Gitega & ZNI & 27 & 17 & 24 & 55 & 31 \\
\hline Kibuye & ZNI & 0 & 1 & 5 & 1 & 2 \\
\hline Mutaho & ZNI & 13 & 2 & 3 & 6 & 1 \\
\hline Ryansoro & ZNI & 4 & 0 & 3 & 4 & 2 \\
\hline Buhiga & ZNI & 0 & 2 & 0 & 2 & 0 \\
\hline Nyabikere & ZNI & 0 & 4 & 0 & 0 & 1 \\
\hline Kayanza & ZNI & 6 & 6 & 8 & 7 & 69 \\
\hline Musema & ZNI & 5 & 7 & 2 & 31 & 8 \\
\hline Gahombo & ZNI & 30 & 25 & 18 & 6 & 15 \\
\hline Mukenke & ZNI & 13 & 4 & 4 & 5 & 0 \\
\hline Vumbi & ZNI & 27 & 26 & 26 & 26 & 1 \\
\hline Makamba & ZNI & 238 & 267 & 249 & 270 & 195 \\
\hline Muramvya & ZNI & 0 & 19 & 3 & 103 & 2 \\
\hline Kiganda & ZNI & 0 & 5 & 6 & 3 & 15 \\
\hline Muyinga & ZNI & 28 & 17 & 8 & 19 & 31 \\
\hline Gashoho & ZNI & 38 & 9 & 1 & 0 & 0 \\
\hline Giteranyi & ZNI & 0 & 22 & 152 & 7 & 12 \\
\hline Kibumbu & ZNI & 10 & 2 & 40 & 4 & 19 \\
\hline Fota & ZNI & 0 & 0 & 0 & 0 & 0 \\
\hline Ngozi & ZNI & 5 & 1 & 0 & 32 & 0 \\
\hline Kiremba & ZNI & 9 & 97 & 3 & 34 & 0 \\
\hline Buye & ZNI & 0 & 0 & 0 & 0 & 0 \\
\hline Rutana & ZNI & 12 & 30 & 15 & 5 & 2 \\
\hline Gihofi & ZNI & 15 & 68 & 72 & 16 & 13 \\
\hline Butezi & ZNI & 9 & 4 & 0 & 5 & 2 \\
\hline Kinyinya & ZNI & 69 & 25 & 99 & 125 & 103 \\
\hline Ruyigi & ZNI & 1 & 1 & 6 & 2 & 1 \\
\hline Mpanda & ZI & 585 & 397 & 307 & 121 & 118 \\
\hline Zone Nord & ZI & 493 & 483 & 215 & 118 & 50 \\
\hline Zone Centre & ZI & 504 & 9 & 70 & 22 & 36 \\
\hline Zone Sud & ZI & 145 & 24 & 23 & 11 & 39 \\
\hline Kabezi & ZI & 115 & 47 & 56 & 174 & 82 \\
\hline$\overline{\text { Isale }}$ & $\mathrm{ZI}$ & 210 & 156 & 71 & 346 & 53 \\
\hline Rumonge & ZI & 189 & 136 & 374 & 213 & 351 \\
\hline Cibitoke & $\mathrm{ZI}$ & 883 & 996 & 901 & 296 & 169 \\
\hline Kirundo & ZI & 10 & 21 & 9 & 12 & 3 \\
\hline Busoni & $\mathrm{ZI}$ & 23 & 23 & 103 & 15 & 4 \\
\hline Nyanza-Lac & ZI & 247 & 315 & 255 & 263 & 149 \\
\hline
\end{tabular}

SD: sanitary district ; ZI : zone of intervention; ZNI : zone of non-intervention; HC: health centre 
Table 2 Analysis of annual trends in intestinal schistosomiasis cases in zones in Burundi that were targeted for MDA with PZQ (ZI) and zones that were not (ZNI).

\begin{tabular}{|c|c|c|c|c|c|c|}
\hline Year & Zone & $\begin{array}{l}\text { SD } \\
(n r)\end{array}$ & $\begin{array}{l}\text { Intestinal schistosomiasis } \\
\text { cases (nr) }\end{array}$ & $\beta$ & $95 \%$ IC & p-value \\
\hline \multirow[t]{2}{*}{2011} & $\mathrm{ZI}$ & 11 & 3404 & 1 & - & - \\
\hline & ZNI & 34 & 876 & 1 & - & - \\
\hline \multirow[t]{2}{*}{2012} & ZI & 11 & 2607 & -0.563 & {$[-1.180 ; 0.054]$} & 0.074 \\
\hline & ZNI & 34 & 856 & -0.157 & {$[-0.757 ; 0.443]$} & 0.607 \\
\hline \multirow[t]{2}{*}{2013} & ZI & 11 & 2384 & -0.521 & {$[-1.140 ; 0.097]$} & 0.098 \\
\hline & ZNI & 34 & 848 & -0.324 & {$[-0.940 ; 0.292]$} & 0.302 \\
\hline \multirow[t]{2}{*}{2014} & ZI & 11 & 1581 & -0.826 & {$[-1.454 ;-0.198]$} & $0.010^{*}$ \\
\hline & ZNI & 34 & 978 & -0.055 & {$[-0.663 ; 0.553]$} & 0.859 \\
\hline \multirow[t]{2}{*}{2015} & $\mathrm{ZI}$ & 11 & 1054 & -1.294 & {$[-1.908 ;-0.680]$} & $<<0.001 *$ \\
\hline & ZNI & 34 & 689 & -0.508 & {$[-1.121 ; 0.105]$} & 0.104 \\
\hline \multirow{2}{*}{$\begin{array}{l}2011- \\
2015\end{array}$} & $\mathrm{ZI}$ & 11 & - & -0.286 & {$[-0.429 ;-0.144]$} & $<0.001^{*}$ \\
\hline & ZNI & 34 & - & -0.087 & {$[-0.227 ; 0.052]$} & 0.219 \\
\hline
\end{tabular}

*: significant; SD: Sanitary district; nr: number; ZI: Zone of intervention, targeted for MDA with PZQ; ZNI: Zone of non-intervention, not targeted for MDA with PZQ

Figures 


\section{$\mathrm{MDA} \rightleftharpoons \mathrm{ZI} \rightleftharpoons \mathrm{ZNI}$}

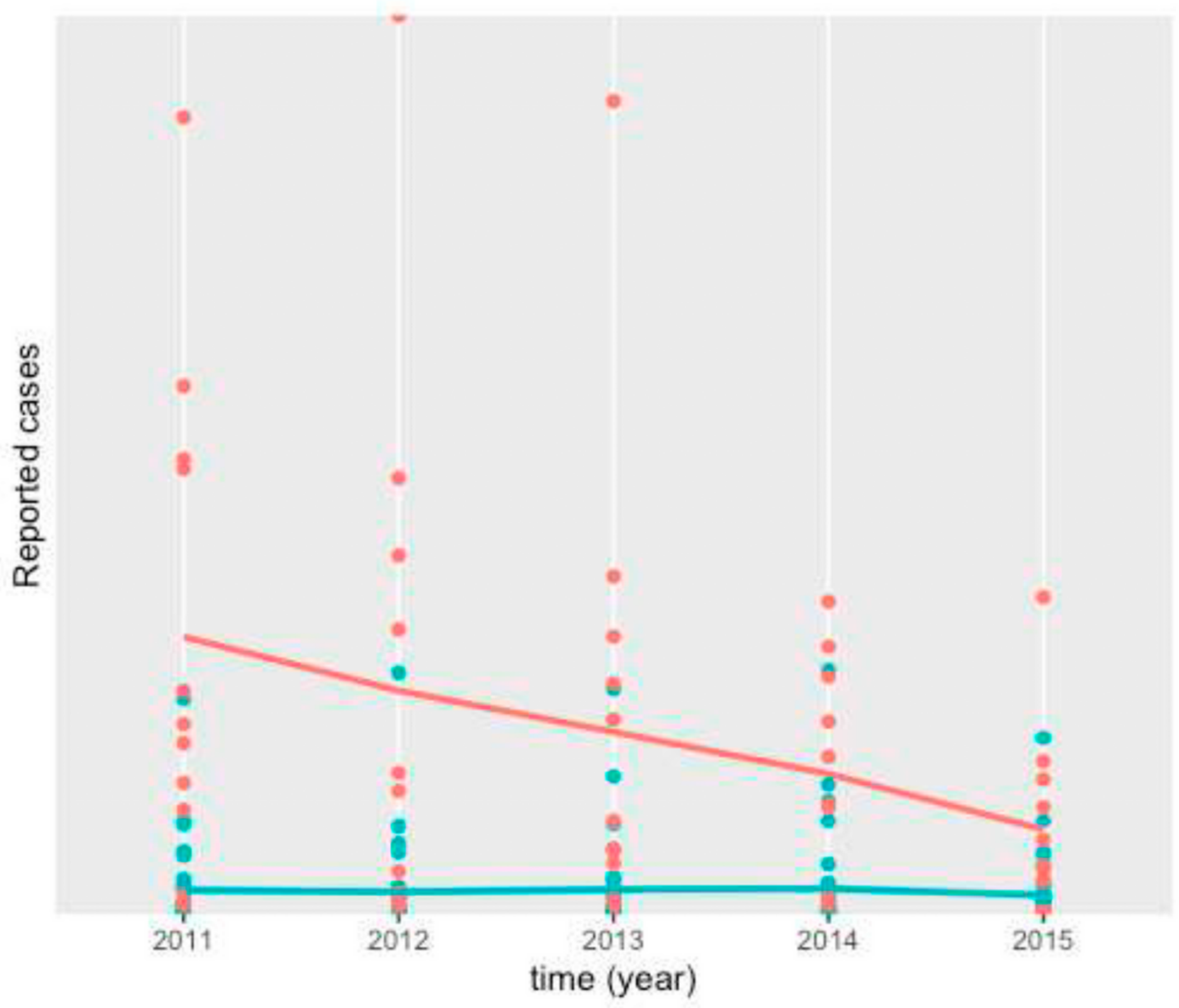

Figure 1

Temporal trends in schistosomiasis in the ZI and in the ZNI ZI: zone of intervention, targeted for MDA with PZQ; ZNI: zone of non-intervention, not targeted for MDA with PZQ 


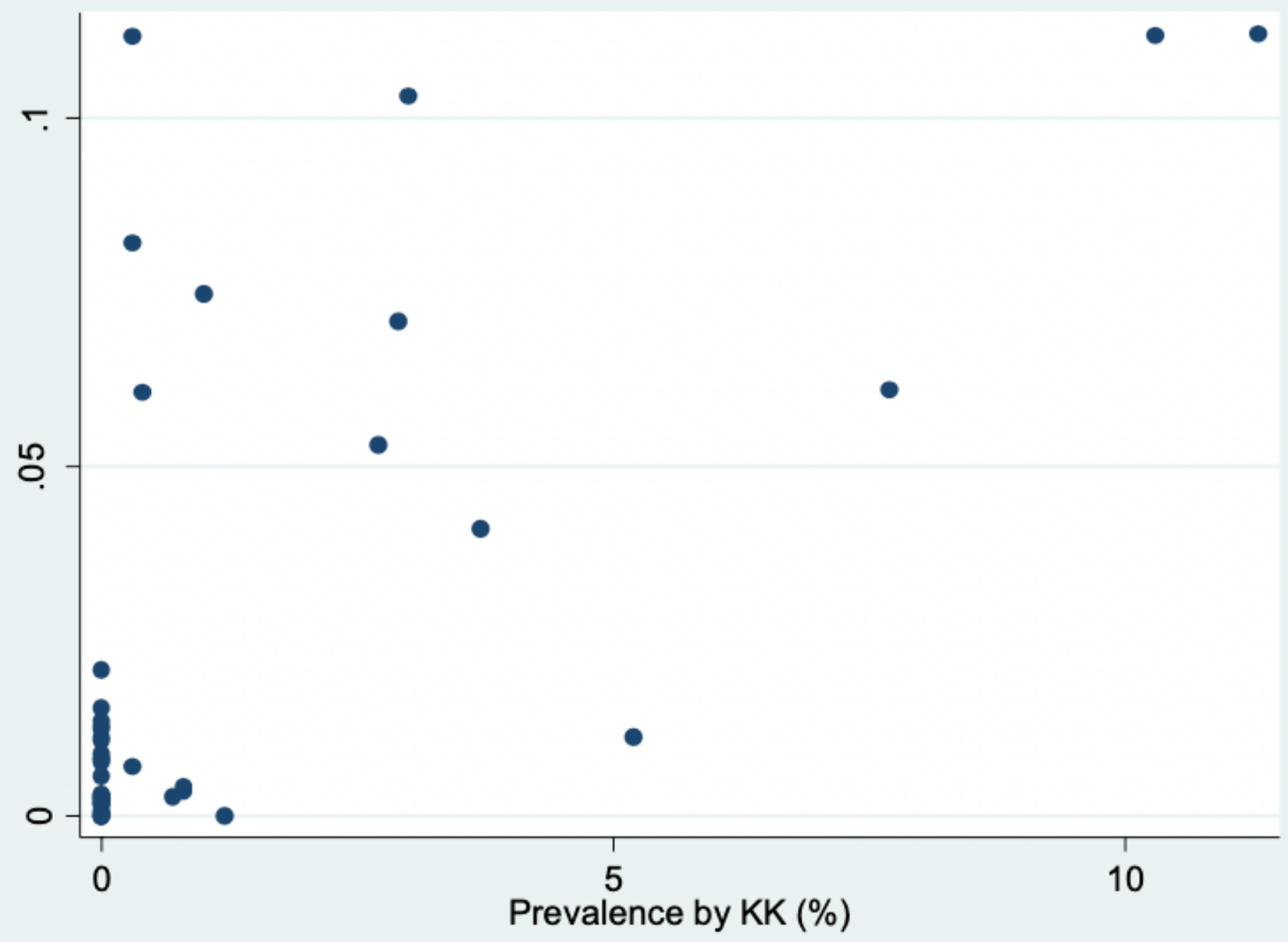

Figure 2

Prevalence (\%) by KK in school children and incidence (\%) by DS at HC level in 2014, Burundi KK: katokatz test; \%: percentage; DS: direct smear; HC: health centre 